\title{
The quality of primary care in community health centers: comparison among urban, suburban and rural users in Shanghai, China
}

Jianwei Shi ${ }^{1,2,3+}$, Hua Jin ${ }^{2,3,4+}$, Leiyu Shi ${ }^{5}$, Chen Chen ${ }^{6}$, Xuhua Ge ${ }^{2,3,4}$, Yuan Lu ${ }^{2,3,4}$, Hanzhi Zhang ${ }^{2,3,4}$, Zhaoxin Wang ${ }^{1,2,3^{*}}$ and Dehua $\mathrm{Yu}^{2,3,4^{*}}$

\begin{abstract}
Objective: Following World Health Organization's initiatives to advance primary care, China put forth forceful policies including the Personal Family Doctor Contract to ensure that every family sign up with a qualified doctor in a community health center (CHC) ever since its 2009 New Health Reform. We used the Johns Hopkins-designed Primary Care Assessment Tool (PCAT) to assess primary care quality experienced by the contracted residents and compare this across different socioeconomic regions.

Methods: Using a multistage sampling method, four CHCs each were randomly selected from urban, suburban and rural districts of Shanghai, a metropolitan with 24 million residents. ANOVA and Multivariate analyses were used to assess the association between location of $\mathrm{CHC}$ and the quality of primary care experience.

Findings: A total of $2404 \mathrm{CHC}$ users completed our survey. Except for the domain of coordination (information systems), users from suburban CHCs reported best primary care experiences in all other domains, followed by users of rural $\mathrm{CHCs}$. After controlling for covariates, suburban $\mathrm{CHC}$ users were more likely to report higher total PCAT scores $(B=1.57, P<0.001)$ compared with those from urban $C H C s$.

Conclusion: That contracted residents from suburban $\mathrm{CHCs}$ reporting better primary care experience than those from urban $\mathrm{CHCs}$ demonstrates the unique value of $\mathrm{CHCs}$ in relatively medical-underserved areas. In particular, urban CHCs could further strengthen first contact (utilization), first contact (accessibility), coordination (referral system), comprehensiveness (available), and community orientation aspects of primary care performance. However, all CHCs could improve coordination (information system).
\end{abstract}

Keywords: Primary care, Community health centers, Quality, PCAT

\footnotetext{
*Correspondence: supercell002@sina.com; shgprc@yeah.net

†Jianwei Shi and Hua Jin are co-first authors on this paper.

'School of Public Health, Shanghai Jiaotong University School of Medicine, 227 Chongqing South RD, Shanghai 200025, China

2Department of General Practice, Yangpu Hospital, Tongji University School of Medicine, 450 Tengyue RD, Shanghai 200090, China

Full list of author information is available at the end of the article
}

(c) The Author(s). 2020 Open Access This article is licensed under a Creative Commons Attribution 4.0 International License, which permits use, sharing, adaptation, distribution and reproduction in any medium or format, as long as you give appropriate credit to the original author(s) and the source, provide a link to the Creative Commons licence, and indicate if changes were made. The images or other third party material in this article are included in the article's Creative Commons licence, unless indicated otherwise in a credit line to the material. If material is not included in the article's Creative Commons licence and your intended use is not permitted by statutory regulation or exceeds the permitted use, you will need to obtain permission directly from the copyright holder. To view a copy of this licence, visit http://creativecommons.org/licenses/by/4.0/ The Creative Commons Public Domain Dedication waiver (http://creativecommons.org/publicdomain/zero/1.0/) applies to the data made available in this article, unless otherwise stated in a credit line to the data. 


\section{Background}

As proposed by World Health Organization (WHO), primary care is a whole-of-society approach that includes health promotion, disease prevention, treatment and rehabilitation, etc. It addresses the majority of a person's health needs throughout their lifetime, and it is peoplecentered rather than disease-centered [1]. A strong focus on primary care contributes to the well-functioning of the health care system overall $[1,2]$. Previous studies have reported that sound primary care, is well provided by general practitioners in community health institutions in the United States, England, New Zealand, Spain, Canada, etc., [3, 4], helping facilitate health care delivery in these countries. By comparison, China's primary care system lagged behind and did not receive enough attention until a big shortage of medical resources occurred and led to a lopsided health care delivery system. In 2009, a new round of healthcare reform was launched nationwide in China, in which the government explicitly set a goal to strengthen primary care [5]. Under this reform, 2200 county hospitals and more than 330,000 clinics and rural township hospitals were reconstructed or upgraded into $\mathrm{CHCs}$ to ensure that a primary care provider is available to all residents living within a 15min transportation radius [5].

In 2011, a personal family doctor contract policy was instituted nationwide to encourage residents to utilize services provided by $\mathrm{CHCs}$ first when seeking out care. Shanghai, as one of the early cities in China to develop $\mathrm{CHCs}$, put forth specific guidelines to implement the contract in providing comprehensive primary care services, including diagnosis and referral services for common diseases, frequently-occurring disease treatment, chronic disease management, public health services, rehabilitation, nursing and other appropriate communitybased medical services [6]. By the end of 2018, there were 6.66 million Shanghai residents (with a sign-up rate of $30 \%$ ) who participated in the " $1+1+1$ " (one $\mathrm{CHC}+$ one regional secondary hospital + one tertiary hospital) family contract program. The sign-up rate for vulnerable populations such as those 65 and over, pregnant, or disabled, reached $54 \%$. For diabetes and hypertension patients, the rate was over $84 \%$ [7]. The reason we only surveyed the contracted residents is that $\mathrm{CHCs}$ regard contracted residents as their responsibility or serving as their usual source of care. The PCAT tool explicitly requires the patient's usual source of care be used to measure his/her primary care experience. Since there is no mandatory restriction on the referral system, any patient in China could bypass $\mathrm{CHC}$ and access big hospitals [8]. Thus, regardless of the severity of the illness, many patients are inclined to choose big hospitals because of better medical technology and perceived technical quality, although the expenditure at the hospital setting is much higher than that at the community $[8,9]$. In China, to promote the residents to utilize primary care, each contracted resident is assigned a family doctor so that interpersonal relation can be established and care coordination facilitated, both of which critical in patient retention [9].

Heretofore, only a few qualitative case studies and commentaries have been written about the primary care experience of patients seeking $\mathrm{CHC}$ care. $\mathrm{Hu}$ et al. (2016) evaluated and compared the quality of primary care provided by different types of health care facilities in Guangdong Province of China. And in Wang et al.'s (2013) study, patients aged 18 years or older who visited their health center on the day of recruitment were asked to report the quality of primary care based on a sample of $\mathrm{CHCs}$ from Guangdong Province [10, 11]. However, these studies did not explicitly focus on patients who visit health centers as their regular source of care. Strictly speaking, the surveyed respondents may not be in a position to report their primary care experience as captured by PCAT since the tool requires usual source of care as the target. Hence, little is known about the primary care quality experienced by contracted $\mathrm{CHC}$ patients and whether there are variations in quality across different socioeconomic regions.

The current study used the primary care assessment tool (PCAT) to examine the quality of primary car experience by $\mathrm{CHC}$ users across different socioeconomic regions. Results of the study not only demonstrates the quality of primary care provided by $\mathrm{CHCs}$ for their contracted users, but also assesses if there are disparities in primary care performance for contract residents across different socioeconomic regions. Although carried out in China, our study could have implications for other cities or regions undergoing urbanization and reorganizing healthcare delivery and further advance the role of $\mathrm{CHCs}$ as a community-based primary care provider.

\section{Methods \\ Study setting}

In this study, we chose Shanghai metropolitan because its primary care system is well-developed and represents one of the best in China. At the end of 2019, Shanghai had a population of 14.50 million registered residents and 9.80 million non-registered residents, and its GDP per capita was the highest in China (113.6 thousand RMB) [12]. Shanghai is also often the pilot of national healthcare reform and policy implementation. Its advanced urbanization but diverse socioeconomic development make it a generalizable region to assess primary care performance by $\mathrm{CHCs}$ across varying socioeconomic regions. 
Due to regional differences in economic and healthcare resources, the primary care in $\mathrm{CHCs}$ varies vastly among different socioeconomic regions. In urban region, the dense distribution of secondary and tertiary hospitals makes residents less inclined to choose $\mathrm{CHCs}$ due to the convenience of accessing higher-level hospitals and the lack of limits on obtaining specialist services [13]. In suburban region, on the other hand, more new projects are stationed and hence more investments. For example, in the suburban Pudong District of Shanghai, a new health reform initiative was launched in 2014, allowing for construction subsidies and talent recruitment to spur CHC development [14-16]. In rural region, the average number of GPs at each $\mathrm{CHC}$ is significantly lower than in urban and suburban areas $[17,18]$.

\section{Data collection}

A multistage sampling method was used (Fig. 1). In stage one, we classified all Shanghai CHCs $(n=244)$ into two groups based on their total quality scores as captured by the 2019 Annual Report of Health Center General Practice Quality Performance [19] (i.e., those ranked in the upper 50 percentile and those ranked in the lower 50 percentile) so that both higher and lower performers would be included in the study. In stage two, we classified all CHCs into three clusters based on their geographic location: urban, suburban or rural. Computergenerated random numbers were then used to choose two $\mathrm{CHCs}$ from each cluster. In stage three, with the help of local government officials and community residential committees, we contacted the randomly selected $\mathrm{CHCs}$ to ask if they would like to participate in our survey. All twelve randomly selected $\mathrm{CHCs}$ agreed to participate in our study. The number of patients selected per $\mathrm{CHC}$ was calculated by first obtaining the value of proportion of patients who responded favourably to PCAT questions through a pilot (i.e., 85\%) and then using $5 \%$ as margin of error. This generated a minimum sample size of 200 per $\mathrm{CHC}$ which was the sample size we used for selecting patients from the targeted population, i.e., the $\mathrm{CHC}$-contracted residents above 40 years of age. Recruited subjects were selected based on three criteria: 1) aged 40 years or above; 2) were contracted residents in the community, and 3) had visited the given $\mathrm{CHC}$ at least twice within the past half year prior to the study. The survey was conducted from August 2019 to December 2019.

\section{Measurement}

Participants' experiences with primary care were measured using the Primary Care Assessment Tool-Adult Edition (PCAT-AE), which was designed by Professor Barbara Starfield and Leiyu Shi of the Primary Care Policy Center at Johns Hopkins University. It focuses on four exclusive attributes: first contact, longitudinality, comprehensiveness, and coordination. Three supplemental attributes, family centeredness, community orientation, and cultural competence, are also included [20]. Initially applied in the US [20], the PCAT gradually acquired international recognition and has been adapted in other countries with diverse health systems, including Canada [21], Spain [22], Brazil [23], Korea [24] and China [23]. The applications represent the level of primary care provided in various regions and countries and can help by providing specific and targeted directions for improvement [20]. PCAT evaluations have credited the $\mathrm{CHC}$ model with providing accessible, cost-effective, and high-quality primary care and reducing health disparities [25, 26]. Its wide adoption across the world makes it a suitable instrument for assessing the quality

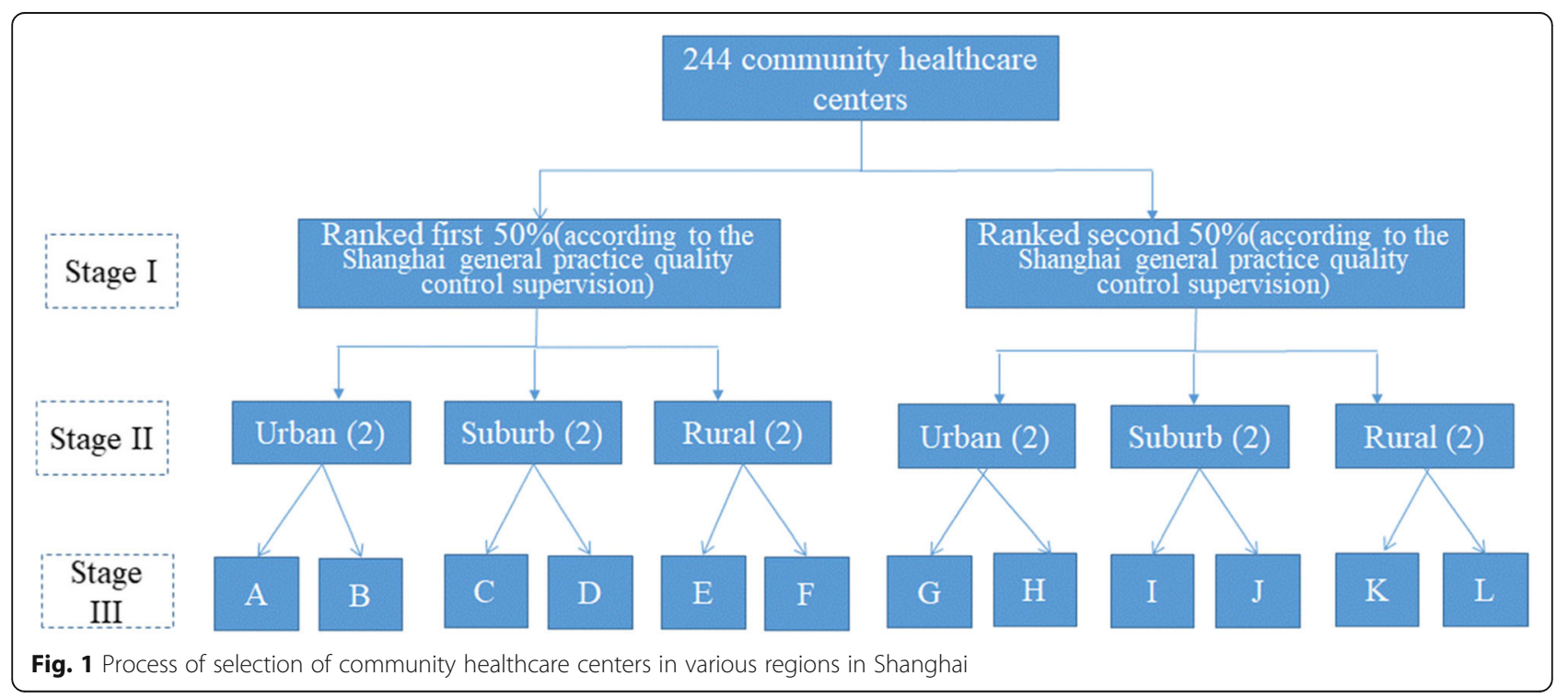


of primary care in China. In addition, the Johns Hopkins' team developed a Chinese version and tested it based on adult samples from the southern part of China (Guangzhou Province) and the western part (Tibet Province), the Chinese version of the PCAT questionnaire was proved to have good reliability and validity $[27,28]$. In this study, we used the Chinese version of the PCAT validated by the Johns Hopkins team. We obtained the designers' consent to use the questionnaire for this study. Data were collected through face-to-face interviews and questionnaires were administered by investigators in the cross-sectional study. Since it was used to collect information from adults' experiences, it was called PCAT-Adult Edition or PCAT-AE. To reduce the presence of interviewer bias, we conducted training with all interviewers prior to actual data collection so that questions and answers were provided consistently. We also conducted a pretest to allow interviewers to practice with actual patients and be monitored. In the early phase of the study, all interviewers were supervised during the actual interview session until they became proficient in administering the questionnaire.

The PCAT-AE was designed to be consistent with the core functions of primary care. A total of 87 items were developed to assess ten domains of participants' primary care experience: first contact (accessibility and utilization), ongoing care, coordination (information and referral systems), comprehensiveness (service availability and service provided), community orientation, familycenteredness, and cultural competence (Table 1). A four-point Likert-type scale was adopted where $1=$ definitely not, $2=$ probably not, $3=$ probably, $4=$ definitely, and $9=$ not sure/don't know (when calculating, 9 was replaced with score of 2.5 based on the PCAT manual). Scores for each domain were derived from the average score of all items within the domain. According to the

Table 1 Interpretation of PCAT-AE Domains

\begin{tabular}{|c|c|c|}
\hline Domain & Number of items & Interpretation \\
\hline 1. First contact-utilization & 3 & General routine examination, first diagnosis of new health problems, etc. \\
\hline 2.First contact-accessibility & 10 & $\begin{array}{l}\text { Business hours, receiving medical treatment in one day, telephone consultation, } \\
\text { evening home visit, appointment for general physical examination, waiting time, } \\
\text { difficulty obtaining medical treatment, expectation value, etc. }\end{array}$ \\
\hline 3.Ongoing care & 14 & $\begin{array}{l}\text { Receiving care from the same physician/nurse, communication with medical staff, } \\
\text { understanding of living and health conditions, etc. }\end{array}$ \\
\hline 4.Coordination (Referral system) & 8 & Referral service between primary care and specialists \\
\hline 5.Coordination (Information system) & 3 & Previous medical records \\
\hline 6.Comprehensiveness (Services available) & 32 & Available medical services in the $\mathrm{CHC}$ \\
\hline 7.Comprehensiveness (Services provided) & 6 & Some of the services involved in the process \\
\hline 8.Family-centeredness & 4 & Family involvement in medical procedures, family history \\
\hline 9.Community orientation & 5 & Family visit, understanding of regional health issues, listening to others \\
\hline 10.Cultural competence & 2 & Recommended to relatives and friends \\
\hline
\end{tabular}

PCAT Manual, higher scores indicate better patient primary care experience $[27,29]$.

In addition, the questionnaire included items about socio-demographic characteristics such as gender, age, marital status, employment status, education, average monthly family income, and health insurance. Items measuring health service utilization were also included, such as the frequency of seeking health services at the $\mathrm{CHC}$, the number of times seeking outpatient service in mental disease lasting over 1 year, and chronic disease.

\section{Analysis}

All data were analysed using SAS Software 9.30. Chisquare tests were conducted to compare sociodemographic characteristics and healthcare utilization of participants among $\mathrm{CHCs}$ in the three geographic areas (i.e., urban, suburban, and rural). Analysis of covariance was used to compare PCAT domain scores and total scores among the three types of CHCs. Multivariate linear regression was then performed to explore the relationship between $\mathrm{CHC}$ type and reported primary care quality (total PCAT score), controlling for respondents' socio-demographic and healthcare utilization measures. Two multiple linear regression models were used to exincluded only $\mathrm{CHC}$ type, while model II controlled for socio-demographic and healthcare utilization measures. Of all the participants, only 851 contracted residents reported experiencing a referral. Therefore, when conducting the multiple linear regressions, total PCAT scores were calculated by summing the mean scores for all domains except coordination (referral system).

\section{Results}

As shown in Table 2, the proportion of respondents from urban, suburban, and rural areas was roughly the past year, self-perceived health status, physical or plore factors associated with PCAT total scores. Model I 
Table 2 Comparison of Participants' Characteristics from CHCs in Urban, Suburban, and Rural Areas of Shanghai

\begin{tabular}{|c|c|c|c|c|c|c|c|c|c|c|c|}
\hline \multirow[t]{3}{*}{ Variable } & \multirow[t]{3}{*}{ Group } & & & \multicolumn{6}{|c|}{ District } & \multirow{3}{*}{$\begin{array}{l}\text { Chi- } \\
\text { square }\end{array}$} & \multirow[t]{3}{*}{$P$ value } \\
\hline & & \multicolumn{2}{|c|}{ Total $(n=2404)$} & \multicolumn{2}{|c|}{ Urban $(n=767)$} & \multicolumn{2}{|c|}{ Suburb $(n=819)$} & \multicolumn{2}{|c|}{ Rural $(n=818)$} & & \\
\hline & & $\bar{N}$ & $\%$ & $\mathrm{~N}$ & $\%$ & $\mathrm{~N}$ & $\%$ & $\mathrm{~N}$ & $\%$ & & \\
\hline \multicolumn{12}{|c|}{ Socio-demographic characteristics } \\
\hline \multirow[t]{2}{*}{ Gender } & Male & 1087 & 45.22 & 329 & 42.89 & 358 & 43.71 & 400 & 48.90 & 6.90 & 0.03 \\
\hline & Female & 1317 & 54.78 & 438 & 57.11 & 461 & 56.29 & 418 & 51.10 & & \\
\hline \multirow[t]{3}{*}{ Age (year) } & $\leq 60$ & 504 & 20.97 & 128 & 16.69 & 207 & 25.27 & 169 & 20.66 & 22.62 & $<0.001$ \\
\hline & $61-70$ & 1149 & 47.80 & 380 & 49.54 & 392 & 47.86 & 377 & 46.09 & & \\
\hline & $>70$ & 751 & 31.24 & 259 & 33.77 & 220 & 26.86 & 272 & 33.25 & & \\
\hline \multirow[t]{2}{*}{ Marital status } & Married & 2377 & 98.88 & 752 & 98.04 & 813 & 99.27 & 812 & 99.27 & 7.03 & 0.03 \\
\hline & Unmarried & 27 & 1.12 & 15 & 1.96 & 6 & 0.73 & 6 & 0.73 & & \\
\hline \multirow[t]{2}{*}{ Employment status } & Employed & 869 & 36.15 & 69 & 9.00 & 223 & 27.23 & 577 & 70.54 & 692.06 & $<0.001$ \\
\hline & Unemployed/retired & 1535 & 63.85 & 698 & 91.00 & 596 & 72.77 & 241 & 29.46 & & \\
\hline \multirow[t]{4}{*}{ Education (missing = 6) } & Primary school or below & 900 & 37.53 & 29 & 3.78 & 383 & 46.76 & 488 & 59.66 & 688.04 & $<0.001$ \\
\hline & Junior school & 848 & 35.36 & 329 & 42.89 & 287 & 35.04 & 232 & 28.36 & & \\
\hline & Senior high school & 450 & 18.77 & 294 & 38.33 & 85 & 10.38 & 71 & 8.68 & & \\
\hline & College or above & 200 & 8.34 & 115 & 14.99 & 64 & 7.81 & 21 & 2.57 & & \\
\hline \multirow{5}{*}{$\begin{array}{l}\text { Average monthly family } \\
\text { income (RMB) }\end{array}$} & $<3000$ & 835 & 34.73 & 35 & 4.56 & 186 & 22.71 & 614 & 75.06 & 967.48 & $<0.001$ \\
\hline & $3000-4000$ & 515 & 21.42 & 225 & 29.34 & 195 & 23.81 & 95 & 11.61 & & \\
\hline & $4001-6000$ & 503 & 20.92 & 259 & 33.77 & 187 & 22.83 & 57 & 6.97 & & \\
\hline & $\geq 6000$ & 305 & 12.69 & 137 & 17.86 & 145 & 17.70 & 23 & 2.81 & & \\
\hline & Not sure & 246 & 10.23 & 111 & 14.47 & 106 & 12.94 & 29 & 3.55 & & \\
\hline \multirow[t]{2}{*}{ Health insurance } & No & 420 & 17.47 & 143 & 18.64 & 115 & 14.04 & 162 & 19.80 & 10.50 & 0.01 \\
\hline & Yes & 1984 & 82.53 & 624 & 81.36 & 704 & 85.96 & 656 & 80.20 & & \\
\hline \multicolumn{12}{|l|}{ Health service utilization } \\
\hline \multirow{4}{*}{$\begin{array}{l}\text { Frequency of seeking } \\
\text { health service in } \mathrm{CHC}\end{array}$} & More than once per month & 1750 & 72.80 & 635 & 82.79 & 600 & 73.26 & 515 & 62.96 & 94.51 & $<0.001$ \\
\hline & Every one to three months & 311 & 12.94 & 71 & 9.26 & 119 & 14.53 & 121 & 14.79 & & \\
\hline & More than every three months & 245 & 10.19 & 43 & 5.61 & 75 & 9.16 & 127 & 15.53 & & \\
\hline & Don't know/Not sure & 98 & 4.08 & 18 & 2.35 & 25 & 3.05 & 55 & 6.72 & & \\
\hline \multirow{4}{*}{$\begin{array}{l}\text { Times seeking outpatient } \\
\text { service in the previous year }\end{array}$} & $\leq 10$ & 801 & 33.32 & 123 & 16.04 & 283 & 34.55 & 395 & 48.29 & 344.99 & $<0.001$ \\
\hline & $10-14$ & 626 & 26.04 & 168 & 21.90 & 251 & 30.65 & 207 & 25.31 & & \\
\hline & $15-20$ & 326 & 13.56 & 123 & 16.04 & 155 & 18.93 & 48 & 5.87 & & \\
\hline & $>20$ & 651 & 27.08 & 353 & 46.02 & 130 & 15.87 & 168 & 20.54 & & \\
\hline \multirow{3}{*}{$\begin{array}{l}\text { Hospitalization in the } \\
\text { previous year (missing }=27 \text { ) }\end{array}$} & 0 & 2084 & 87.67 & 665 & 86.70 & 729 & 89.01 & 690 & 84.35 & 14.8 & 0.01 \\
\hline & 1 & 231 & 9.72 & 86 & 11.21 & 61 & 7.45 & 84 & 10.27 & & \\
\hline & $\geq 2$ & 62 & 2.61 & 13 & 1.69 & 18 & 2.20 & 31 & 3.79 & & \\
\hline \multirow[t]{2}{*}{ Self-perceived health status } & Poor/Fair & 1381 & 57.45 & 504 & 65.71 & 342 & 41.76 & 535 & 65.40 & 125.02 & $<0.001$ \\
\hline & Good/Excellent & 1023 & 42.55 & 263 & 34.29 & 477 & 58.24 & 283 & 34.60 & & \\
\hline Physical or mental disease & Yes & 527 & 21.92 & 155 & 20.21 & 202 & 24.66 & 170 & 20.78 & 34.95 & $<0.001$ \\
\hline & No & 1698 & 70.63 & 579 & 75.49 & 563 & 68.74 & 556 & 67.97 & & \\
\hline & Not sure & 179 & 7.45 & 33 & 4.30 & 54 & 6.59 & 92 & 11.25 & & \\
\hline Chronic disease & Yes & 2141 & 89.06 & 705 & 91.92 & 716 & 87.42 & 720 & 88.02 & 9.58 & 0.01 \\
\hline & No & 263 & 10.94 & 62 & 8.08 & 103 & 12.58 & 98 & 11.98 & & \\
\hline
\end{tabular}


similar (31.91, 34.07 and 34.03\%, respectively). In total, there were more female (54.78\%), 61-70-year-old $(47.80 \%)$, married $(98.88 \%)$, and unemployed/retired (63.85\%) respondents. Most individuals' highest education was either primary school or below (37.44\%) or junior school (35.27\%), and $34.73 \%$ had an average monthly family income $<3000$ RMB. $82.53 \%$ had health insurance. In terms of health service utilization, the majority sought services at $\mathrm{CHCs}$ more than once per month (72.80\%). A higher proportion sought outpatient services less than 10 times in the previous year (33.32\%), followed by $>20(27.08 \%)$ and $10-15$ times (26.04\%). The majority respondents did not have inpatient hospitalization in the previous year (86.69\%). Most respondents reported poor/fair health status (57.45\%), and most also reported having no physical or mental disease lasting over 1 year (70.63\%). The majority of participants had at least one chronic disease (89.06\%).

Table 2 also compares the socio-demographic characteristics and health service utilization among urban, suburban, and rural $\mathrm{CHC}$ users. Similar to the total distribution, participants in each area were more likely to be female, 61-70 years of age, married, unemployed/ retired. There were less proportion of participants with an educational attainment at the junior or senior high school or above level in rural area. Also, more rural participants had $<3000$ RMB monthly family income and were without health insurance. Regarding healthcare utilization, more urban residents visited $\mathrm{CHC}$ more than once per month and had outpatient services $>20$ times in the previous year. Urban residents were also more likely to have at least one chronic disease but had no physical or mental disease lasting over 1 year.

$\mathrm{CHC}$ users generally reported high quality primary care experience especially in the domain of first-contact (utilization), family centeredness, and comprehensiveness (services provided). Specifically, the scores for first contact (utilization) (mean $=3.68)$, first contact (accessibility) $($ mean $=3.06)$, ongoing care $($ mean $=3.31)$, coordination (referral system) $($ mean $=3.32)$, comprehensiveness (available $) \quad($ mean $=3.45), \quad$ comprehensiveness $\quad$ (provided) $($ mean $=3.45)$, community orientation $($ mean $=3.26)$, culturally competent $($ mean $=3.37)$ were significantly higher for suburban participants $(P<0.001)$. However,

Table 3 Comparison of Various PCAT Domains among CHCs in Urban, Suburban, and Rural Areas

\begin{tabular}{|c|c|c|c|c|c|}
\hline \multirow[t]{2}{*}{ Domain } & & \multicolumn{3}{|l|}{ District } & \multirow[t]{2}{*}{$P$ value } \\
\hline & & Urban & Suburb & Rural & \\
\hline \multirow[t]{2}{*}{ First contact (Utilization) } & Mean & $3.34^{c}$ & $3.68^{\mathrm{A}}$ & $3.50^{B}$ & $<0.001$ \\
\hline & SE & 0.62 & 0.43 & 0.56 & \\
\hline \multirow[t]{2}{*}{ First contact (Accessibility) } & Mean & $2.57^{\mathrm{B}}$ & $3.06^{\mathrm{A}}$ & $3.02^{\mathrm{A}}$ & $<0.001$ \\
\hline & SE & 0.44 & 0.34 & 0.48 & \\
\hline \multirow[t]{2}{*}{ Ongoing care } & Mean & $3.13^{B}$ & $3.31^{\mathrm{A}}$ & $3.05^{c}$ & $<0.001$ \\
\hline & SE & 0.39 & 0.31 & 0.48 & \\
\hline \multirow[t]{2}{*}{ Coordination (Referral system) } & Mean & $3.07^{\mathrm{B}}$ & $3.32^{\mathrm{A}}$ & $3.25^{\mathrm{A}}$ & $<0.001$ \\
\hline & SE & 0.72 & 0.49 & 0.51 & \\
\hline \multirow[t]{2}{*}{ Coordination (Information system) } & Mean & $2.82^{\mathrm{A}}$ & $2.68^{B}$ & $2.78^{\mathrm{A}}$ & $<0.001$ \\
\hline & SE & 0.35 & 0.41 & 0.36 & \\
\hline \multirow[t]{2}{*}{ Comprehensiveness (Available) } & Mean & $2.97^{C}$ & $3.45^{\mathrm{A}}$ & $3.17^{B}$ & $<0.001$ \\
\hline & SE & 0.67 & 0.36 & 0.55 & \\
\hline \multirow[t]{2}{*}{ Comprehensiveness (Provided) } & Mean & $3.15^{\mathrm{B}}$ & $3.45^{\mathrm{A}}$ & $3.17^{\mathrm{B}}$ & $<0.001$ \\
\hline & SE & 0.56 & 0.41 & 0.57 & \\
\hline \multirow[t]{2}{*}{ Family centeredness } & Mean & $3.35^{\mathrm{A}}$ & $3.36^{\mathrm{A}}$ & $3.11^{\mathrm{B}}$ & $<0.001$ \\
\hline & SE & 0.62 & 0.59 & 0.66 & \\
\hline \multirow[t]{2}{*}{ Community orientation } & Mean & $2.96^{C}$ & $3.26^{\mathrm{A}}$ & $3.10^{B}$ & $<0.001$ \\
\hline & SE & 0.64 & 0.52 & 0.61 & \\
\hline \multirow[t]{2}{*}{ Culturally competent } & Mean & $3.14^{\mathrm{B}}$ & $3.37^{\mathrm{A}}$ & $2.99^{C}$ & $<0.001$ \\
\hline & SE & 0.61 & 0.63 & 0.61 & \\
\hline \multirow[t]{2}{*}{ Total- PCAT } & Mean & $27.42^{c}$ & $29.61^{A}$ & $27.90^{B}$ & $<0.001$ \\
\hline & SE & 3.17 & 2.47 & 3.49 & \\
\hline
\end{tabular}


coordination (information systems) was perceived highest in urban (mean $=2.82)(P<0.001)$. When comparing the urban and rural areas, it was found that rural $\mathrm{CHCs}$ perceived better in terms of first contact (utilization) $($ mean $=$ 3.50 ), first contact (accessibility) (mean $=3.02$ ), coordination $($ referral system) $($ mean $=3.25)$, comprehensiveness (available) $($ mean $=3.17)$, and community orientation $($ mean $=3.10)($ Table 3$)$.

The multiple linear regression models indicated that geographic area was significantly associated with total PCAT scores in model I (Table 4). After controlling for socio-demographics and health service utilization, participants in suburban $\mathrm{CHCs}$ were more likely to report higher total PCAT scores compared to urban participants $(B=1.57, P<0.001)$. Respondents who perceived higher total PCAT scores were also more likely to be older in age $(61-70$ years: $\beta=-0.60, P<0.001 ;>70$ years: $B=-0.52, P=0.01)$. Also, those with a college education or above $(\beta=0.81, P<0.001)$, with an average monthly family income of $\geq 6000 \mathrm{RMB}(B=-1.24, P<0.001)$, had $>20$ outpatient visits in the previous year $(\beta=-1.81, P<$ 0.001 ), and with self-perceived good/excellent health statuses $(B=0.35, P=0.01)$ reported significantly lower total PCAT scores.

\section{Discussion}

By using the internationally developed and Chinese validated PCAT, we examined contracted residents' primary care experience in $\mathrm{CHCs}$ situated in urban, suburban, and rural areas of Shanghai Metropolitan. Overall, even though respondents in our study generally reported positive experience with their primary care services, it was found that they gave lower PCAT scores than patients from $\mathrm{CHCs}$ in the US. This could to some extent be accounted for by the use of different PCAT versions $[27,30]$. Nevertheless, the main explanation might be due to China's still under-developed primary health care system, especially when compared with developed countries. However, in our study, the absolute differences in domains and total PCAT scores for CHCs across different geographic areas were small, which was comparable to a previous study conducted in other regions of China [11]. When comparing with the other China-based studies, the total PCAT score was a little lower than that of a study conducted in the Guangdong Province [8]. This disparity may be caused by sample differences and the survey tool used. Our study focused on contracted residents who more frequently utilized both medical and health management services provided by $\mathrm{CHCs}$ whereas previous study included all $\mathrm{CHC}$ users regardless of their usual source of care. Also, the study conducted in the Guangdong Province used an abbreviated version of the PCAT (where only 25 items were used to assess the seven domains of primary care), which had significant differences from the PCAT-AE (where 87 items were developed to assess ten domains of participants' primary care experience) used in our study. The more abundant and competitive medical services provided in larger hospitals in Shanghai may also lead to worse perceptions of primary care at $\mathrm{CHCs}$.

Interestingly, comparing the perceptions of $\mathrm{CHCs}$ in various regions within Shanghai indicated that contracted patients at suburban $\mathrm{CHCs}$ perceived higher total PCAT scores, followed by patients at urban and rural CHCs. In Shanghai and other regions in China, $\mathrm{CHC}$ revenue and expenditure are separate, meaning that $\mathrm{CHCs}$ obtain all their subsidies from financial investment. The amount of governmental investment is set by the amount of service provided by the $\mathrm{CHC}$ in the previous year [31]. As such, $\mathrm{CHC}$ development is largely dependent on regional subsidies and the state of surrounding competitive health institutions. Urban areas of Shanghai contain an abundance of secondary and tertiary hospitals. As no strict referral system exists in China [32], the operation of urban CHCs is largely influenced by fewer financial subsidies that may have an impact on primary care quality. Due to advanced urbanization planning, regional suburban governments obtain more financial investment from the Shanghai municipal government [32]. There is also less competition as fewer large hospitals exist in the suburbs. These added benefits are conducive to $\mathrm{CHC}$ development and may improve the quality of primary care in suburban areas. However, comparing rural and urban areas, residents' perceived PCAT scores were not significantly different, which is not consistent with a previous study conducted in the Guangdong province [33]. This may also be explained by greater competition experienced in urban area (compared to rural area) but less investment received (compared with suburb area) [32].

Regarding the various domains of the PCAT, our results showed that $\mathrm{CHCs}$ in suburban districts performed the best in all PCAT domains except for coordination (information systems). This domain represents the convenience of access to patients' electronic medical records and was found to be best in urban CHCs. This can be explained by the fact that information system development was undertaken by the local urban district for both $\mathrm{CHCs}$ and higher-level hospitals. Benefiting from a unified information construction effort, $\mathrm{CHCs}$ in urban areas acquired better access to patient medical information [34]. However, among all individual domain scores on the PCAT, the average score for information systems was still the lowest. This indicates that much can be done to improve this specific area. It should be noted that ongoing care/continuity is particularly important for primary care patients, as contracted residents are more likely to use health services more frequently and 
Table 4 Linear Regressions on Total PCAT Scores

\begin{tabular}{|c|c|c|c|c|c|c|c|}
\hline \multirow[t]{2}{*}{ Variable } & \multirow[t]{2}{*}{ Group } & \multicolumn{3}{|c|}{ Model I } & \multicolumn{3}{|c|}{ Model II } \\
\hline & & $\bar{B}$ & T value & $P$ value & $\bar{B}$ & T value & $P$ value \\
\hline \multirow[t]{3}{*}{ District } & Urban & Ref. & & & Ref. & & \\
\hline & Suburban & 2.18 & 14.16 & $<0.001$ & 1.57 & 8.90 & $<0.001$ \\
\hline & Rural & 0.47 & 3.05 & $<0.01$ & -0.21 & -0.93 & 0.35 \\
\hline
\end{tabular}

Socio-demographic characteristics

$\begin{array}{ll}\text { Gender } & \text { Male } \\ \text { Age (year) } & \text { Female } \\ & \leq 60 \\ & 61-70 \\ & >70 \\ \text { Marital status } & \text { Married } \\ & \text { Unmarried } \\ \text { Employment status } & \text { Employed } \\ & \text { Unemployed/retired } \\ \text { Education } & \text { Primary school or below } \\ & \text { Junior school } \\ & \text { Senior high school } \\ & \text { College or above } \\ \text { Average monthly } & <3000 \\ \text { family income (RMB) } & 3000-4000 \\ & 4001-6000 \\ & \geq 6000 \\ & \text { Not sure } \\ \text { No } & \text { Yes } \\ \text { Health insurance } & \end{array}$

\section{Health service utilization}

$\begin{array}{ll}\begin{array}{l}\text { Frequency of seeking } \\ \text { health service in CHC }\end{array} & \text { More than once per month } \\ & \text { Every one to three months } \\ & \text { More than every three months } \\ & \text { Don't know/Not sure } \\ & \leq 10 \\ \text { Times seeking outpatient } & 10-15 \\ \text { service in the previous year } & 15-20 \\ & >20 \\ \text { Times seeking inpatient } & 0 \\ \text { service in the previous year } & 1 \\ & \geq 2 \\ \text { Self-perceived health status } & \text { Poor/Fair } \\ \text { Physical or mental disease } & \text { Good/Excellent } \\ \text { lasting over one year } & \text { Yes } \\ \text { Chronic disease } & \text { No } \\ \text { Adjusted R square } & \text { Not sure } \\ & \text { Yes } \\ & \text { No }\end{array}$

More than once per month

Every one to three months

More than every three months

Ref.

$\begin{array}{lll}-0.07 & -0.57 & 0.57 \\ \text { Ref. } & & \\ -0.60 & -3.51 & <0.001 \\ -0.52 & -2.79 & 0.01 \\ \text { Ref. } & & \\ -0.63 & -1.11 & 0.27 \\ \text { Ref. } & & \\ 0.18 & 1.15 & 0.25 \\ \text { Ref. } & & \\ -0.22 & -1.34 & 0.18 \\ -0.13 & -0.63 & 0.53 \\ 0.81 & 3.11 & <0.001 \\ \text { Ref. } & & \\ -0.07 & -0.34 & 0.73 \\ -0.33 & -1.62 & 0.11 \\ -1.24 & -5.21 & <0.001 \\ -2.07 & -8.46 & <0.001\end{array}$

Ref.

$\begin{array}{lll}0.20 & 1.25 & 0.21\end{array}$

Ref.

$\begin{array}{lll}-0.66 & -3.15<0.001\end{array}$

$\begin{array}{lll}-0.56 & -2.38 & 0.02\end{array}$

$\begin{array}{lll}0.02 & 0.07 \quad 0.94\end{array}$

Ref.

$\begin{array}{lll}-0.34 & -1.81 & 0.07\end{array}$

$\begin{array}{lll}0.02 & 0.10 \quad 0.92\end{array}$

$\begin{array}{lll}-1.81 & -9.27 \quad<0.001\end{array}$

Ref.

$\begin{array}{lll}0.05 & 0.27 & 0.79\end{array}$

$\begin{array}{lll}0.43 & 1.13 & 0.26\end{array}$

Ref.

$\begin{array}{lll}0.35 & 2.58 & 0.01\end{array}$

Ref.

$\begin{array}{lll}-0.49 & -3.20<0.001\end{array}$

$\begin{array}{lll}-1.48 & -5.75 & <0.001\end{array}$

Ref.

$\begin{array}{lll}-0.81< & -3.70<0.001\end{array}$

0.086

0.204 
can benefit from a closer patient-provider relationship [8]. However, $\mathrm{CHCs}$ in rural areas have much room for improvement in this domain. Regarding the other domains of first contact (utilization), first contact (accessibility), coordination (referral system), comprehensiveness (available), and community orientation, higher scores were given in rural areas than urban areas. This could possibly be due to the following factors: convenient travel distance to $\mathrm{CHCs}$, no appointments required, and shorter waiting time in rural $\mathrm{CHCs}$ [8]. These results differ from an early study based on a sample of 645 adult users from Canada (in Quebec and Nova Scotia), which reported poorer first-contact access in rural areas than in urban areas [35].

Our results indicated that respondents who were older and in relatively good health would perceive higher total PCAT scores. This was consistent with a Korean study based on sample data collected from patients whose usual source of care came from family doctors working at nine private clinics. The Korean Primary Care Assessment Tool also found that primary care quality was positively associated with good self-rated health status [36]. It also found that those with an education of college or above and higher average income would perceive significantly lower total PCAT scores. This may be caused by participants in these groups being more inclined to seek out higher-level hospitals for care. Another previous study in China found that compared with other types of health care facilities, tertiary hospital users had higher proportions of patients with higher education, employment and income levels [8].

Several limitations must be taken into account for this study. First, although the sampling of $\mathrm{CHCs}$ was randomly chosen in the cross-sectional study, the sampling of contracted residents was not well-randomized. Participants were selected at each $\mathrm{CHC}$ as they were seeking out services, making the age of our sample relatively old. Second, survey data were based entirely off of selfreports and thus may be subject to recall bias. Third, the study examined contracted patients' subjective experiences of primary care rather than objective health outcomes. Patients' perceived experiences may vary as a result of their expectations and unique characteristics.

\section{Conclusion}

The finding showed that suburban $\mathrm{CHC}$ users reported better total primary care experience than urban $\mathrm{CHCs}$, demonstrating the unique value of $\mathrm{CHCs}$ in relatively medical underserved areas. That suburban $\mathrm{CHC}$ residents reporting better primary care experience than those from urban $\mathrm{CHCs}$ demonstrates the unique value of $\mathrm{CHCs}$ in relatively medical-underserved areas. In particular, urban $\mathrm{CHCs}$ should strengthen first contact (utilization), first contact (accessibility) and coordination (referral system) aspects of primary care performance. However, all CHCs should improve coordination (information system). To improve residents' experiences of primary care, relevant policies including a strict referral system to ensure $\mathrm{CHCs}$ play a gatekeeping role should be implemented. Adequate funding for $\mathrm{CHCs}$ should also be provided, especially for those in urban areas. For $\mathrm{CHCs}$ in suburban and rural areas, measures should be used to improve their rudimentary information systems. This study may provide evidence for global countries or regions undergoing urbanization to better improve their primary care quality.

\section{Abbreviations}

CHCs: Community healthcare centers; PCAT: Primary care assessment tool; WHO: World health organization; PCAT-AE: Primary care assessment tooladult edition

\section{Acknowledgements \\ We sincerely acknowledge and appreciate the assistance of community healthcare centers in Shanghai for their help in collecting the data.}

\section{Authors' contributions}

Conceived and designed the study: JWS, LYS and DHY. Analyzed the data: HJ, CC, and XHG. Contributed reagents/materials/analysis tools: YL, HZZ, and ZXW. Wrote the paper: JWS and ZXW. All authors have read and approved the manuscript.

\section{Funding}

The design of this study was supported by the Shanghai Excellent Young Talents Project in Health System (2018YQ52). Data extraction and analysis was funded by the Natural Science Foundation of China (71774116; 71603182). The interpretation of data guided by the statisticians were funded by grants from the National Key R\&D Program of China (2018YFC2000700) and Shanghai Medicine and Health Development Foundation (Se1201931). The writing and revision, including the language improvement, were sponsored by Shanghai Pujiang Program (2019PJC072) and Shanghai Leading Talents Program (YDH-20170627).

\section{Availability of data and materials}

The datasets generated and/or analysed during the current study are available in the Figshare repository (https://figshare.com/s/f9172352bd91f11 bf85f).

\section{Ethics approval and consent to participate}

We acquired the written informed consent from the study participants. This study was approved by the Ethics Committees of Tongji University (ref: LL2016-ZRKX-017). Participant personal information was not available to individuals who did not participate in the research.

\section{Consent for publication}

Not applicable.

\section{Competing interests}

The authors have declared that no conflict of interest exists.

\section{Author details}

${ }^{1}$ School of Public Health, Shanghai Jiaotong University School of Medicine, 227 Chongqing South RD, Shanghai 200025, China. ${ }^{2}$ Department of General Practice, Yangpu Hospital, Tongji University School of Medicine, 450 Tengyue RD, Shanghai 200090, China. ${ }^{3}$ Shanghai General Practice and Community Health Development Research Center, Shanghai 200090, China. ${ }^{4}$ Academic Department of General Practice, Tongji University School of Medicine, 450 Tengyue RD, Shanghai 200090, China. ${ }^{5}$ Department of Health Policy and Management, Primary Care Policy Center, Johns Hopkins University, Baltimore, MD 21205, USA. ${ }^{6}$ Shanghai Jing 'an District Jiangning Road Community Health Service Center, Shanghai 200041, China. 
Received: 15 May 2020 Accepted: 19 August 2020

Published online: 27 August 2020

\section{References}

1. World Health Organization. (2020). Primary health care. https://www.who. int/health-topics/primary-health-care\#tab=tab_1. Accessed May 2, 2020.

2. Waddington R. Portugal's rapid progress through primary health care. Bull World Health Organ. 2008;86(11):826-7.

3. Kringos D, Boerma W, Bourgueil Y, Cartier T, Dedeu T, Hasvold T, et al. The strength of primary care in Europe: an international comparative study. $\mathrm{Br}$ J Gen Pract. 2013;63(616):E742-50.

4. Chen Z. Launch of the health-care reform plan in China. Lancet. 2009; 373(9672):1322-4

5. Yip W, Hsiao W. Harnessing the privatisation of China's fragmented healthcare delivery. Lancet. 2014;384(9945):805-18.

6. Shanghai Municipal People's Government. (2015). Guiding Opinions on Further Promoting the Comprehensive Reform and Development of the Municipal Community Health Service. http://www.shanghai.gov.cn/nw2/nw2314/ nw32792/nw38917/nw38919/u26aw41751.html. Accessed April 23, 2020.

7. Shanghai Municipal People's Government. (2013). Guidance on the comprehensive promotion of family doctor system in this city. https://www yicai.com/news/100095345.html. Accessed April 23, 2020.

8. Xiao, N., Long, Q., Tang, X., et al. (2014). A community-based approach to non-communicable chronic disease management within a context of advancing universal health coverage in China: Progress and challenges. BMC Public Health, 14(Suppl 2):S2 https://doi.org/https://doi.org/10.1186/ 1471-2458-14-S2-S2. Epub 2014 Jun 20.

9. Shi L, Sun Y, Nie X, Meng Q. Job satisfaction by Chinese primary care doctors under health care reform. China Health Policy Manage (Chin J). 2013;4(3):15-27.

10. Hu RW, Liao Y, Du ZC, Hao YT, Liang HL, Shi L. Types of health care facilities and the quality of primary care: a study of characteristics and experiences of Chinese patients in Guangdong Province, China. BMC Health Serv Res. 2016;16:335.

11. Wang HH, Wong SY, Wong MC, et al. Patients' experiences in different models of community health centers in southern China. Ann Fam Med. 2013;11(6):517-26.

12. Shanghai Statistics Bureau. (2017). Statistical bulletin of Shanghai's national economic and social development (2016). http://www.stats-sh.gov.cn/html/ sjfb/201703/293816.html. Accessed April 23, 2020.

13. Cai LQ, Hou J, Lu XJ. Effectiveness evaluation of on-the-job training for general practitioners in rural community health service center in the outlying suburbs of Shanghai. Chin J Gen Pract. 2019;17(02):256-8.

14. People's Daily Online. (2014). Eight Reform Tasks of Health and Family Planning Work in Pudong New Area for this year. http://sh.people.com.cn/ n/2014/0331/c215689-20895302.html.

15. Liu M. Financing policy research on the community health Services in a Certain District of Shanghai. Shanghai Jiaotong University Dissertation; 2015.

16. Gao SR, Li YT, Liu SS, Lou JQ, Jing Y, Zhou SY, et al. Reflect on the health integration development of urban and rural region in Pudong new area. Chin Prim Health Care. 2014;28(10):21-4.

17. Chen R. Analysis on the running and equity evaluation on the allocation of health resources of community health service centers in Shanghai from 2013 to 2011. The Second Military Medical University Dissertation; 2013.

18. Zhang A. Research on community health service efficiency and evidencebased analysis in Shanghai. Shanghai Jiaotong University Dissertation; 2014.

19. Shanghai Clinical Quality Center of General Practice. Expert Consultation Questionnaire of the Construction of Clinical Quality Control Standard System for General Practice in Shanghai Community Health Center (the second round). 2019. https://www.wjx.cn/jq/32558871.aspx. Accessed 2 May 2020.

20. Shi L, Starfield B, Xu JH. Validating the adult primary care assessment tool. J Fam Pract. 2001;50(2):161-75.

21. Haggerty $J$, Burge F, Beaulieu MD, Pineault R, Beaulieu C, Levesque JF, et al. Validation of instruments to evaluate primary healthcare from the patient perspective: overview of the method. Healthc Policy. 2011;7(S):31-46.

22. Pena FV, Harzheim E, Terrasa S, Berra S. Psychometric validation in Spanish of the Brazilian short version of the primary care assessment tools-users questionnaire for the evaluation of the orientation of health systems towards primary care. Aten Primaria. 2017;49(2):69-76.

23. Harzheim E, Pinto LF, D'Avila OP, Hauser L. Brazilian National Institute of geography and statistics (IBGE) in partnership with Brazilian Ministry of
Health launch the major national household survey using primary care assessment tool (PCAT) in the world. J Fam Med Prim Care. 2019;8:4042-3.

24. Cho Y, Chung H, Joo H, Park HJ, Joh HK, Kim JW, et al. Comparison of patient perceptions of primary care quality across healthcare facilities in Korea: a cross-sectional study. PLoS One. 2020;15(3):e0230034.

25. Shi L, Lee DC, Chung M, Liang H, Lock D, Sripipatana A. Patient-centered medical home recognition and clinical performance in U.S. community health centers. Health services research. 2016. https://doi.org/10.1111/14756773.12523.

26. Probst JC, Laditka JN, Laditka SB. Association between community health center and rural health clinic presence and county-level hospitalization rates for ambulatory care sensitive conditions: an analysis across eight US states. BMC Health Serv Res. 2009;9:134-69.

27. Shi $\mathrm{L}$, Starfield B, Xu JH. Validating the adult primary care assessment tool. J Fam Pract. 2001;50(2):161-74

28. Yang H, Shi L, Lebrun LA, Zhou X, Liu J, Wang H. Development of the Chinese primary care assess-ment tool: data quality and measurement properties. Int J Qual Health Care. 2013;25(1):92-105. https://doi.org/10. 1093/intghc/mzs072.

29. Starfield B, Shi L. Manual for the primary care assessment tools: John Hopkins University Press; 2009.

30. Flocke SA, Miller WL, Crabtree BF. Relationships between physician practice style, patient satisfaction, and attributes of primary care. J Fam Pract. 2002; 51(10):835-40.

31. $X u X$, Zhou L, Antwi HA, Chen X. Evaluation of health resource utilization efficiency in community health centers of Jiangsu Province, China. Hum Resour Health. 2018;16(1):13

32. Wang ZX, Shi JW, Wu ZG, Xie HL, Yu YF, Li P, et al. Changes in chronic disease management among community health centers (CHCS) in China: has health reform improved the CHC ability? Int J Health Plann Manag. 2017;32(3):317.

33. Hu R, Liao Y, Du Z, Hao Y, Liang H, Shi L. Types of health care facilities and the quality of primary care: a study of characteristics and experiences of Chinese patients in Guangdong Province, China. BMC Health Serv Res. 2016; 16:335.

34. He JJ, Zhong H, Tang ZQ, Zhang TY, Kang Q, Wang HP, et al. Comprehensive evaluation of community health services in Shanghai in 2015. Chin Gen Pract. 2017;20(34):4242-7.

35. Haggerty $J$, Bouharaoui F, Santor DA. Differential item functioning in primary healthcare evaluation instruments by french/english version, educational level and urban/rural location. Health Policy. 2011;7(spec issue): 47-65.

36. Sung NJ, Markuns JF, Park KH, Kim K, Lee H, Lee JH. Higher quality primary care is associated with good self-rated health status. Fam Pract. 2013;30(5): 568-75

\section{Publisher's Note}

Springer Nature remains neutral with regard to jurisdictional claims in published maps and institutional affiliations.

Ready to submit your research? Choose BMC and benefit from:

- fast, convenient online submission

- thorough peer review by experienced researchers in your field

- rapid publication on acceptance

- support for research data, including large and complex data types

- gold Open Access which fosters wider collaboration and increased citations

- maximum visibility for your research: over $100 \mathrm{M}$ website views per year

At BMC, research is always in progress.

Learn more biomedcentral.com/submissions 